\title{
Black Female Images in Iola Leroy
}

\author{
Yan Lin*, Weifeng Huang
}

Hangzhou Dianzi University, Hangzhou, China

${ }^{*}$ Corresponding author. Email: lyj1997jia@qq.com

\begin{abstract}
Iola Leroy, the representative work of Frances Harper, is one of the first novels published by African American women. This novel mainly portrays three images of black women-rebels, dedicators and seekers for equality. They fought against slavery and racial discrimination in their own ways, or devoted their talents and energy to their race, or pursued educational equality and economic equality. Such new positive images, which are in sharp contrast to the negative stereotypes depicted in White American literature, form an important part of African American women literary tradition.
\end{abstract}

Keywords: Iola Leroy, Black female image, Rebels, Dedicators, Equality seekers.

\section{《艾奥拉・勒洛伊》中的黑人女性形象}

\author{
林燕”, 黄卫峰
}

杭州电子科技大学, 杭州, 中国

“通讯作者. 邮箱: 1yj1997jia@qq.com

中文摘要

弗朗西斯・哈珀的代表作《艾奥拉・勒洛伊》是美国黑人女性创作出版的第一批小说之一。这部小说主要塑造 了三种黑人女性形象一一反抗者、奉献者、平等追求者。她们或者通过自己独特的方式反抗奴隶制及种族歧视， 或者为黑人民族无私奉献自己的才华和精力, 或者追求教育和经济平等。这些黑人女性形象与当时美国主流文 学中关于黑人女性的公式化形象形成鲜明对象, 成为美国黑人女性文学传统的重要组成部分。

关键词: 《艾奥拉・勒洛伊》; 黑人女性形象; 反抗者; 奉献者; 平等追求者.

\section{1. 引言}

内战前, 美国主流文学所构建的黑人女性形象可 以概括为三种: 顺从的保姆、放荡的情妇、妖魔化的 女巫。这些形象对黑人女性进行了歪曲, 不仅为白人 对黑人女性的压迫提供了合理的借口, 还从心理上对 黑人女性造成影响, 导致她们厌恶自我, 怀疑自我。 因此要彻底解放黑人女性, 就必须解构传统的刻板形 象, 重塑黑人女性真实的自我, 这是黑人女性作家的 首要任务。

美国非裔作家弗朗西斯·哈珀是19世纪著名的女性 废奴主义者。她以笔为武器, 与蓄奴制斗争, 曾先后
出版多部诗集及小说。她看到战后黑奴虽获得解放, 种族歧视却愈演愈烈, 于是创作了小说《艾奥拉. 勒洛 伊》（1892）。这是最早由美国黑人女性创作出版的 小说之一。小说描写了美国内战期间以艾奥拉为主的 黑白混血儿支持联邦政府、英勇战斗，以及战后在极 端不利的条件下艰苦创业的状况。小说塑造了以艾奥 拉为代表的一群黑人女性新形象，对内战前的美国主 流文学所构建的黑人女性刻板形象进行了解构。本文 拟从反抗者、奉献者、平等追求者三个方面对《艾奥 拉·勒洛伊》中的黑人女性形象进行分析。 


\section{2. 作为反抗者的黑人女性}

美国奴隶制在人类历史上具有独特性。这种独特 性主要体现在两个方面。首先, 它不是基于经济状况, 而是基于种族。第二, 它不仅是一种经济剥削制度, 而且是一种性剥削制度。黑人女性除了与黑人男性一 样遭受经济压迫之外, 还是奴隶主性剥削的主要受害 者。在小说《艾奥拉. 勒洛伊》中, 黑人女性不仅对奴 隶主的性侵犯进行反抗，而且在内战期间积极参与废 除奴隶制的斗争, 并通过拒绝与白人结婚的方式对种 族歧视提出抗议。

小说中，主人公艾奥拉在其为奴期间对白人主人 的性侵进行反抗。奴隶制时期, 许多黑人女性惨遭主 人的性侵或性虐。奴隶主与奴隶发生性关系, 有的是 为了满足自己的生理欲望, 还有的是为了繁殖更多的 奴隶, 从而获取更大的经济利益。白人奴隶主为了使 性侵合理化, 把黑人女性描写成放荡的情妇, 称之为 “耶洗别”。这种公式化形象成为黑人女性的标签, 是 白人统治阶级种族歧视的产物, 也是他们延续奴隶制、 压迫黑人种族的借口。（孙麟, 2018：59）因此, 揭 穿白人奴隶主性侵的真相、解构放荡的情妇形象成为 黑人女性作家的重要历史使命。哈珀在小说中描写了 艾奥拉遭到白人奴隶主性侵时反抗的场景。艾奥拉出 生在一个混血家庭, 本来是自由人的身份。后来, 她 父亲死于黄热病, 她的叔叔阿尔弗雷德·洛林因凯觎 遗产, 便设计把艾奥拉沦为奴隶。在奴隶主家中, 她 “被鲁莽自私的主人卑劣地监禁着”。白人奴隶主曾试 图性侵她, “把她拉到罪恶和耻辱的最底层”, 但是由 于艾奥拉的强烈反抗，他的罪恶企图没有得逞。

(Harper, 2010:73) 艾奥拉拼死捍卫自己贞操的行为充 分说明, 黑人女性并非放荡不羁。

小说中的黑人女性还通过积极参与内战来反抗奴 隶制。其中最典型的就是琳达阿姨。与惟命是从、愚 昧无知的黑人保姆传统形象不同, 琳达不仅憎恨白人 统治, 而且充满智慧。琳达阿姨是艾奥拉祖母家的奴 隶, 在内战期间她积极参与到反抗奴隶制的斗争中, 通过在黑人社区传达内战消息来帮助自己的民族。由 于奴隶不能直接参与内战, 琳达阿姨便借用黄油来传 递战争的消息, 用新鲜的黄油 (fresh butter) 喻指联邦 军队的胜利; 用不新鲜的或者变质的黄油(rancid or stale butter)来指代联邦军队的失败。琳达阿姨对奴隶 制的反抗还表现在她对学习标准英语的排斥。她认为, 黑人英语是黑人特有的种族遗产, 而学习标准英语则 会削弱黑人的种族遗产。为此, 琳达阿姨不愿意读书, 因为在她看来, 读书意味着要学习标准英语。

艾奥拉在婚姻上的选择体现了黑人女性对种族歧 视的抗议。奴隶制时期, 在白人占据统治地位的情况 下, 白人对黑人存在严重的种族歧视。普通白人男性 都不愿与黑人女性结婚。因此, 对于某些黑人女性来 说, 能与白人男性结婚是求之不得的事情。但在小说 中, 艾奥拉拒绝了白人医生格雷沙姆先生的求婚。她 这样做不是因为不喜欢格雷沙姆, 而是出于对阿尔弗
雷德等白人亲戚的憎恨。作为一名浅肤色黑白混血儿, 她还拒绝了格雷沙姆劝她冒充白人的建议。最后, 艾 奥拉选择了一位志同道合的黑人男性作为自己的伴 侣。这表明，她不想接受白人男性父权制的保护 (Carby, 1987:90)，而是把自己的命运与黑人种族联 系在一起。她决心帮助刚获得自由的奴隶改善自己的 生活条件。

\section{3. 为黑人种族奉献的黑人女性}

《艾奥拉·勒洛伊》之前，在美国主流文学中，黑 人保姆往往是为白人家庭提供无私的奉献, 因为她们 往往把白人家庭看的比自己家庭更为重要, 对白人主 人家庭的爱甚至远超过对自己家庭的爱。黑人女性主 义批评家柯林斯认为, 如果没有这种扭曲的意识, “种 族、阶级和社会压迫就不可能继续下去”。（Collins, 2000:67）由此可见，只有修正黑人女性被扭曲的思想 意识, 才能提升黑人民族。在《艾奥拉. 勒洛伊》中, 黑人女性不再是为白人无私奉献, 而是为黑人无私奉 献。这种奉献表现在才华和精力两个方面。

小说中露西尔·德拉妮是用自己才华为黑人做出奉 献的典型黑人女性。露西尔·德拉妮是一名纯血统的 黑人女性, 也是小说中受教育程度最高的黑人女性, 她把自己的注意力放在黑人女性的发展上。首先, 她 通过开办学校来对黑人女性进行教育。她之所以开办 学校, 是因为“有一天, 她在报纸上看到黑人妇女已经 不再适合做白人的仆人, 那么她们也不适合做自己孩 子的母亲”。她希望通过开办学校来“培养未来的妻子 和母亲。”(Harper, 2010: 202) 最初她把学校设在一所 不起眼的小房子, 很快就取得了令人满意的效果。后 来, 她扩大了学校的规模, 增加了教学力量。露西 尔·德拉妮不仅通过开办学校来提升黑人女性的素质, 还向黑人女性传达进步的思想。她在座谈会中发表演 讲，向黑人女性宣传反对奴隶制的观点。

艾奥拉是小说中为黑人不断奉献精力的典型代表。 内战期间, 大量的士兵受伤, 艾奥拉被安排到医院当 护士。她不仅悉心照料受伤的黑人士兵, 而且还用自 己的歌声给他们带来心灵上的慰藉。“那清新又年轻 的声音出奇地富有同情心, 使她对每一个需要她温柔 呵护的人都充满了爱心”。(Harper, 2010:73) 内战结束 后，艾奥拉投身到帮助黑人发展的事业中。如前文所 述, 艾奥拉拒绝格雷沙姆的一个重要原因是她想帮助 南方的黑人。她认为, 那里的黑人需要自己并且感激 自己。她不仅在学校担任教师, 还曾参与管理“全国已 婚及未婚妇女培训学校”, 从事把来自南方农村的黑人 妇女培训成合格家政服务员的事业。艾奥拉把个人的 生存与发展升华为对整个黑人民族的热爱并孜孜不 倦地为改善黑人命运而工作, 这是她作为一名黑人女 性对自己的民族所做出的奉献。 


\section{4. 作为平等追求者的黑人女性}

在白人文化占主导地位的父权社会，黑人女性是 美国社会中边缘的边缘, 长期以来处于无语的状态。 在小说中, 艾奥拉是一名努力为黑人女性发声的社区 领袖。作为一名独立自主的女性, 她不仅追求教育平 等, 倡导女性接受教育, 而且追求经济平等, 鼓励黑 人女性同胞出去寻找工作，保持经济独立。

奴隶制时期, 南方的种植园主为了维护并延续奴 隶制度, 制定了严格的法律禁止奴隶接受教育, 目的 是从思想上麻痹黑人奴隶, 使他们接受自己被奴役的 地位。因此, 内战结束后, 如何帮助黑人获得教育, 改善黑人的政治、经济状况和社会处境, 促进黑人社 会地位的提升, 成为黑人领袖的使命。在小说中, 艾 奥拉始终强调黑人女性接受教育的重要性。(Jackson, 2003:555)她认为, 黑人女性只有接受教育, 才能提升 整个黑人民族。艾奥拉不仅自身接受了良好的教育, 还帮助黑人同胞接受教育。她在教育中既注重传授知 识, 也努力培养黑人的品格, 让他们成为好公民。在 她的帮助之下, 来自方圆几英里的学生来到她的学校 学习。这些人当中, 有的是戴着眼镜的老人, 那一双 双在奴隶制的阴影下变得黯淡的眼睛, 努力地辨认着 一字一句。

艾奥拉也是一名追求经济平等的独立女性。根据 黑人女性主义批评家柯林斯的观点, 奴隶制时期, 美 国黑人妇女长期扮演着黑人保姆的角色, 是廉价劳动 力的重要来源, 帮助维持中产阶级和白人工人阶级家 庭的阶级地位。作为家政工人, 她们不论受到白人 “家 庭”多么得爱戴, 依靠微薄的收入还是不能自立, 因为 她们在资本主义政治经济中受到经济剥削。（Collins, 2000:74）在小说中, 尽管舅舅罗伯特告诉艾奥拉没有 必要出去工作, 但她依然坚持挣钱养家。因为她觉得 许多罪恶和痛苦都源于女人的软弱与无能。她告诉罗 伯特舅舅, 每个女人都应该有某种技能或艺术, 至少 可以让自己生活地舒服。她相信, 如果女性更加尊重 劳动或以劳动为荣, 不幸福的婚姻就会减少。战争期 间, 她曾在联邦医院做过护士, 战后做过推销员和教 师。因此, 艾奥拉有着自己的工作和收入来源, 在经 济上可以自给自足, 不需要获得其他人的帮助。

\section{5. 结语}

在美国历史上, 黑人女性不仅遭受种族压迫, 而且 遭受性歧视。因此, 反抗种族歧视和性别歧视成为美 国黑人女性作家的重要历史使命。废奴主义黑人女性 作家哈珀的小说《艾奥拉. 勒洛伊》有力地驳斥了美国 主流文学所刻画的黑人女性消极刻板形象, 构建了黑 人女性的新形象, 成为黑人女性文学传统的重要组成 部分。这种积极的黑人女性形象, 成为 20 世纪黑人女作 家塑造新黑人女性形象的滥解。(Elkins, 1990: 52) 哈 莱姆文艺复兴时期, 佐拉. 尼尔·赫斯顿在《他们眼望 上苍》中塑造的具有独立思想的珍妮是这种黑人女性
文学传统的进一步发展与完善。因此, 在某种意义上, 哈珀可以被视为黑人女权主义的先锋。

\section{致谢}

在此论文完成之际, 我要感谢我的导师黄卫峰教 授，他严谨细致、一丝不苟的作风一向是我工作、学 习中的榜样。在写论文的过程中, 遇到了很多问题, 在老师的耐心指导下, 一个个问题都得以解决。所以 在此, 再次对老师道一声: 老师, 谢谢您！同时感谢 我的家人和朋友们, 让我能专心完成此篇文稿。再次 感谢大家对我的帮助和支持!

最后, 诚挚地感谢各位评阅本论文的专家教授, 感 谢你们的耐心评阅！

\section{REFERENCES}

[1] Carby, H. V. Reconstructing Womanhood: The Emergence of the Afro-American Woman Novelist[M]. Oxford: Oxford University Press on Demand, 1987.

[2] Collins, P. H. Black Feminist Thought: Knowledge, Consciousness, and the Politics of Empowerment[M]. New York: Routledge, 2000.

[3] Elkins, M. Reading Beyond the Conventions: A Look at Frances EW Harper's Iola Leroy, or Shadows Uplifted[J]. American literary realism, 1870-1910 22, no. 2 (1990): 44-53.

[4] Harper, F. E. W. Iola Leroy, or Shadows Uplifted[M]. New York: Penguin Books, 2010.

[5] Jackson C. I Will Gladly Share with Them My Richer Heritage": Schoolteachers in Frances EW Harper's" Iola Leroy" and Charles Chesnutt's" Mandy Oxendine[J]. African American Review, 2003, 37(4): 553-568.

[6] Sun Lin. Revisiting the Herstory of Black Motherhood: A Black Feminist Perspective[J]. Journal of World Peoples Studies,2018(03):55-63. 